\title{
AN ECOLOGICAL ANALYSIS OF COMPETITION AMONG U.S. COMMUNITIES
}

\author{
PINO AUDIA \\ Dartmouth College
}

Tuck School of Business

\author{
JENNIFER KURKOSKI \\ Haas School of Business \\ University of California, Berkeley
}

\begin{abstract}
August 2011
Forthcoming in Industrial and Corporate Change Special issue in John Freeman's memory
\end{abstract}

We would like to thank Howard Aldrich, Paul Ingram, Chick Perrow, Woody Powell, Chris Rider, Martin Ruef, two anonymous reviewers, and seminar participants at Stanford University and New York University for helpful comments. The late John Freeman provided invaluable advice and encouragement. 


\title{
AN ECOLOGICAL ANALYSIS OF COMPETITION AMONG U.S. COMMUNITIES
}

\author{
ABSTRACT \\ We apply the ecological concept of the organization's niche pioneered by John Freeman and \\ Mike Hannan to the study of geographic communities. We define a community's market niche \\ by the ties linking a community to the industries on which it depends for growth. We then \\ hypothesize that the extent to which a community’s market niche is occupied by other \\ communities is a source of constraint and opportunity depending on the geographical locations \\ of the communities that occupy the same market niche. Geographically distant communities \\ occupying similar market niches are hypothesized to experience primarily constraint arising from \\ competition for opportunities of exchange. Geographically proximate communities occupying \\ similar market niches are hypothesized to face constraint arising from competition for exchange \\ opportunities as well as opportunity arising from access to valuable resources associated to the \\ existence of similar others. Empirical analyses of firm foundings and exits across U.S. \\ communities support these hypotheses. Implications of our findings for ecological research on \\ the niche and for the literature on communities are discussed.
}




\section{INTRODUCTION}

A growing and influential body of work suggests that the fate of communities, defined as geographically bounded areas where people live and work, is greatly affected by internal community processes. The literature on agglomerations, for example, points to internal attributes that influence the location choices of firms (Chung and Alcacer, 2002), foundings (Klepper, 2002), and the circulation of information (Almeida and Kogut, 1999). Other organizational analyses of communities call attention to ecological (Sorenson and Audia, 2000; McKendrick et al., 2003), institutional (Lounsbury 2007; Marquis and Lounsbury, 2007), and social network processes (Ingram and Lifschitz 2006; Fleming, King, and Juda 2007) that take place inside communities.

Less known and less investigated is the impact on communities of external processes, especially those arising from inter-community relations. Studies of positions in geographic space have been especially important in advancing understanding of inter-community relations (Hedstrom, 1994; Greve, 2002). Geographic space, however, is not the only space in which communities exist (Freeman and Audia, 2006). Other systems of relations, including those arising from migration flows (Rosenkopf and Almeida, 2003), market exchange (Audia, Freeman, and Reynolds, 2006), and intra- (Alderson and Beckfield, 2004) and interorganizational relations (Davis and Greve, 1997; Whittington, Owen-Smith, and Powell, 2009), link communities. So communities that appear distant when viewed in geographic terms can be proximate when different kinds of relations are considered.

In this study we seek to extend this emerging literature on inter-community relations by applying to communities the ecological concept of an organization's niche developed by John Freeman and Mike Hannan. In organizational ecology terms, a niche is a location in a 
multidimensional resource space in which a set of social actors can survive and reproduce (Hannan and Freeman, 1977, 1989; Freeman and Hannan, 1983). Scholars have explored the concept of niche in fine-grained analyses applied primarily at the organizational level, defining niches along a variety of dimensions such as the types of products offered (Freeman and Hannan, 1983; Dobrev, Kim, and Hannan, 2001), socio-demographic characteristics of organizational members (Baum and Singh, 1994; McPherson, 1983), organizational form and identity (Ruef, 2000), organizational ideologies (Ingram and Simons, 2000; Barnett and Woywode, 2004), and kinds of technologies (Podolny, Stuart, \& Hannan, 1996). Beyond organizations, the niche concept sheds light on dynamics at other levels of analysis as well. Researchers, for example, apply it to the study of interest groups (Gray and Lowery, 1996), occupations (Rotolo and McPherson, 2001), cultural tastes (Mark, 1998), and industries (Burt and Carlton, 1989; Sorensen 2004). Here we draw on the niche concept to develop an analysis of how communities compete against each other.

Competition among communities may occur on a variety of dimensions. Communities aim to attract and retain public investments (Martin and Rogers, 1995; Altshuler and Luberoff, 2003), entice skilled workers (Saxenian, 2005; Marx, Strumsky, and Fleming, 2009), and even attempt to distinguish themselves as wedding destinations (Tying the Knot in Las Vegas). In this study we concentrate on a dimension of community competition that arises from the market exchanges undertaken by communities’ constituent firms (Audia, Freeman, and Reynolds, 2006). Specifically, we focus on attempts by a community's constituent firms to place their goods beyond the boundary of the community in which they reside and define a community's market niche on the basis of the kinds of goods a community's constituent firms seek to place in the 
market - footwear versus chemicals, electronics versus apparel. In other words, the industries on which a community depends for growth define the niche it occupies in the market.

Ecologists distinguish between two types of competition: direct competition, which involves taking actions directed to inhibit the growth of other actors, and indirect or diffuse competition, which typically arises from occupying the same niche in resource space and does not require awareness of the existence of competitors (Carroll and Hannan, 2000: 225). Our focus in this paper is on indirect or diffuse competition among geographically bounded communities and for the sake of brevity hereafter we use the term competition to refer to this form of competition.

Besides not requiring awareness of the existence of competitors, diffuse competition between social entities does not require communication and coordination among members of the competing social entities. ${ }^{1}$ The growth or decline of an organizational population, for example, hinges on the ability of its members to survive and reproduce. When members of an organizational population occupy a niche in resource space intensively targeted by members of other organizational populations, irrespective of whether they coordinate their efforts, declines in survival and reproduction imply decline and possibly even extinction of the organizational population (e.g., Ruef, 2004a, 2004b). Similarly, rich traditions of research on cities and regions in sociology (Duncan et al., 1960; Bluestone and Harrison, 1982; Markusen 1994), economic geography (Tiebout, 1962; Glaeser et al., 1992; Scott 1998), and organizational ecology (Carroll and Wade, 1991; Lomi, 1995; Ingram and Inman, 1996) suggest or imply that the growth or decline of geographically bounded communities are inextricably linked to the ability of their constituent organizations to survive and reproduce.

\footnotetext{
${ }^{1}$ Although coordination among members of a population is not a prerequisite to the study of diffuse competition, studies suggest tha coordination among members of a population impacts inter-population competition (Ingram and Inman, 1996; Ingram and Rao, 2004)
} 
In addition to applying the concept of the niche to geographic communities, we seek to extend niche theory by addressing an apparent point of disagreement between niche theory and research on social networks and agglomerations. Research on the niche suggests that similarity breeds constraint in the form of intensified competition, as actors with similar environmental dependencies pursue the same resources. In contrast, research on social networks and the literature on agglomerations suggest that the existence of similar others who face similar challenges arising from common environmental dependencies increases the availability of valuable resources. Network theorists emphasize the circulation of information among similar others (Burt, 1987; Ingram and Roberts, 2000; White, 2002; Ingram and Lifschitz, 2006) whereas agglomeration scholars focus on information but also access to skilled workers and specialized suppliers (Marshall, 1890; Krugman, 1991; Saxenian, 1994; Porter, 2000). These literatures imply that occupying a crowded niche may be beneficial.

If both of these effects are likely to be operating simultaneously and if any net effect is likely to be due to variance in the relative strength of each, one approach to disentangling the effects of these two processes is to identify those conditions likely to influence the strength of these diverging effects in different ways. Drawing on the literature on agglomerations, we suggest that geography may offer such a conditioning factor, as the strength of the beneficial effects of similarity is conditional on the locations that similar others occupy in geographical space. Specifically, we propose that being near to similar others solely in the resource space may bring the constraint of resource scarcity without the advantages provided by market similarity. On the other hand, being near to similar others in geographical space, while also a constraint, offers easier access to the resources associated to the existence of similar producers valuable information, skilled workers, and specialized suppliers. That is, for a strong mutualistic 
effect to occur between two communities along with a competitive effect requires that those communities be located next to each other in geographic space.

We begin by developing the conception of a community's market niche. We then advance hypotheses linking communities’ positions in market space and geographical space to firm foundings and exits. In the section that follows, we describe the data sources andthe variables and the models we used to test the hypotheses. After reviewing the results, we conclude with a broader discussion of our findings.

\section{A COMMUNITY'S MARKET NICHE}

Organizational research that uses the concept of the niche (Hannan and Freeman, 1989; Hannan, Carroll, and Polos, 2003) draws on modern ecological theory, in particular the work of Elton and Hutchinson. Elton (1927) defined the niche as a population's role in a community, a way of earning a living, and offered an evocative bridge between animal species and social actors noting that "when an ecologist says 'there goes a badger' he should include in his thoughts some definite ideas of the animal's place in the community to which it belongs, just as if he had said 'there goes the vicar.' "' To Elton's definition, Hutchinson (1957) added precision, defining the niche as the set of environmental conditions within which a population can reproduce itself. Application of these ideas to organizations was pioneered by John Freeman and Mike Hannan who, in their niche width theory (Freeman and Hannan, 1983), examine the consequences of occupying a narrow or a broad niche under varying environmental conditions. Two additional early contributions to the literature on the organization's niche served as catalysts for subsequent work. First, whereas John Freeman and Mike Hannan (1983) in their niche width theory focus their attention on the fundamental niche, the multidimensional social space in which an 
organization can grow or sustain itself independent of the presence of competitors, Glenn Carroll's (1985; Carroll and Swaminathan, 2000) analysis of the competitive dynamics between generalist and specialist organizations illustrates some of the rich theoretical implications that can be derived from focusing on the realized niche - a subset of the fundamental niche in which an organization can grow and sustain itself in the presence of competitors. Second, Miller McPherson (1983), in a study of voluntary associations and their dependence on different kinds of volunteers, while also focusing on realized niches, operationalizes niches in network terms, as sets of relations, thus laying the ground for the use of social network methodologies in the study of organizations’ niches (DiMaggio, 1986; Burt, 1992).

Since these early applications of the concept of the niche to organizations, researchers have broadened the analysis to single inventions (Podolny and Stuart, 1995), individuals (Popielarz and McPherson, 1991), individual organizations (Baum and Singh, 1994; Dobrev et al., 2001; Podolny et al., 1996), and even national industries (Burt, 1992; Sorensen, 2004). The strong appeal of the concept of the niche among sociologists and organizational theorists owes in large part to the fact that it embodies the fundamental sociological insight that the position that social actors occupy, whatever the level of aggregation at which social actors are defined, is a primary determinant of opportunity and constraint.

In studies of competition, scholars have focused largely on those relations that tie actors to resource providers (Hannan and Freeman, 1977; White, 1981, 2002; Burt and Carlton, 1989; Baum and Singh, 1994; Sorensen 2004). These scholars argue that two actors that depend on the same resource providers have a similar pattern of market relations and thus occupy the same niche or position in the market. For example, MacPherson (1983), in the study mentioned above, examines voluntary organizations' pursuit of potential recruits. Working at the organizational 
level, he defines the niche by the kinds of people to whom a given voluntary organization appeals - e.g., young versus old, more educated versus less educated. For these voluntary organizations, the resource is membership, and two voluntary organizations that aim to recruit the same kinds of members have the same set of ties to resource providers. Consequently, they occupy the same niche. Similarly, at the level of whole industries, Burt (Burt and Carlton, 1989; Burt 1992) delineates market niche by tracing an industry's upstream ties to its suppliers and downstream ties to its customers. He suggests that two industries occupy a similar market niche if they make similar purchases from the same suppliers and similar sales to the same customers.

Just as voluntary organizations target different members and industries target different suppliers and customers, a community's constituent firms target different opportunities of exchange in the market for goods (Audia et al., 2006). The industries to which a community's constituent firms belong define the kinds of goods they seek to place - electronics versus apparel, footwear versus chemicals. So a community's market niche can be defined by the kinds of relations linking it to the industries on which it depends for growth. By virtue of the mix of industries present in a community, communities' constituent firms pursue some opportunities for exchange but not others. Thus, it is possible to draw ties between communities and the industries on which they depend for their growth. Communities that have the same pattern of ties to industries pursue the same kind of opportunities for exchange in the market for the placement of goods. We focus on these ties to define which niches communities occupy in the market structure. In the Data and Methods section we provide detailed examples of the market niches occupied by a sample of six U.S. communities - Los Angeles, CA; New York City, New York; Chicago, Illinois; Boston, Massachusetts; Bakersfield, California; and Dickinson, North Dakota. 


\section{A COMMUNITY'S MARKET NICHE OVERLAP}

The next step in our analysis is to identify those features of a community's market niche that may have an impact on economic activities. We focus here on overlap in market niches, a dimension that has attracted considerable attention in previous studies (Hannan and Freeman, 1977; MacPherson, 1983; Baum and Singh, 1994; Podolny et al., 1996; Ruef, 1997; Dobrev et al., 2001; Sorensen, 2004). In our analysis, overlap in the market niches of two communities indicates similarity in the two communities' patterns of ties to various resources. Perfect overlaps occur when two communities have identical industrial profiles and are rare. More common are situations of partial overlaps, meaning that one community targets some - but not all - of the same industries targeted by another community. However, our concern is not simply with the overlap between any given pair of communities, but rather with the extent to which a community's market niche overlaps with all communities in an urban system. Overlap at the level of the whole system, as opposed to that of any given pair, takes on additional important meaning as system-level overlap indicates the extent to which a particular community's niche is a unique and open niche or crowded full of similar others.

The organizational ecology literature (Baum and Singh, 1994; Podolny et al., 1996; Ruef, 1997; Dobrev et al., 2001; Sorensen, 2004) suggests that the extent to which a niche is crowded generally intensifies competition (Hannan and Freeman, 1977, 1989; MacPherson, 1983; Hannan et al., 2007). ${ }^{2}$ Put simply, resource claims by similarly positioned actors expand with the number and magnitude of overlaps. The increasing resource demands resulting from market

\footnotetext{
${ }^{2}$ Organizational ecologists acknowledge an exception to this prediction: when the social actors occupying the same niche lack legitimacy, increasing density of similar others produces mutualistic effects stemming from the growth of constitutive legitimation up to the point in which legitimation effects hit a ceiling (Hannan et al., 2007: 197). While constitutive legitimation might apply to community level processes, it is not a key feature of the market processes examined in this study because we are focusing on manufacturing industries whose social acceptance is well established.
} 
niche overlaps pit similarly positioned actors against each other: that is, the efforts of one actor limit the probability that another actor will succeed. In considering the fates of a given community, a high level of overlap in market niche suggests that the community's firms will face stiff competition in finding and maintaining customers. The implication of this literature for our analysis is that the more crowded a community's niche, the more its constituent firms are constrained in their attempts to place their goods. Furthermore, as resource competition intensifies, other actors are dissuaded from occupying that niche (Baum and Singh, 1994; Sorensen, 2004). Therefore, high levels of market niche overlap will result not only in a greater number of a community's firms disbanding but also in a greater number of would-be entrepreneurs abandoning their plans for establishing new firms.

Although ample empirical evidence supports the idea that occupying a crowded niche may be harmful, two distinct literatures - the literature on markets-as-networks and the literature on agglomerations - suggest that similar dependence on resources may also be beneficial. According to White (1981, 2002; see also: Porac et al., 1995) cognitive limitations induce similarly positioned producers to watch each other to gather clues that might help them make decisions on such crucial matters as production volumes and quality levels. Like White, Burt (1987) theorizes that similarly positioned actors monitor each other more than actors who have dissimilar patterns of ties, although in Burt's analysis this monitoring is driven more by the fear of being replaced by similarly positioned actors than it is by attempts to overcome cognitive limitations. Despite these subtle differences, both views rest on the idea that structurally equivalent actors use monitoring to gather information from each other and that they use that information to make decisions intended to improve their standing. 
The literature on agglomerations echoes and expands the idea that similar producers may benefit from each other (Marshall, 1890; Krugman, 1991; Saxenian, 1994; Porter 2000). Like White and Burt, scholars of agglomerations identify the circulation of valuable information among producers as a key benefit arising from similarity. White and Burt see the circulation of information arising from monitoring whereas the agglomeration literature, as we explain in greater detail below, recognizes the importance of a broader range of mechanisms of information circulation including interfirm mobility of skilled workers (Almeida and Kogut, 1999) and interpersonal relations among individuals who hold similar kinds of expertise (Saxenian, 1994). Agglomeration researchers point to two additional benefits stemming from similarity (Marshall, 1890; Krugman, 1991; Porter 2000). The first is easier access to deep specialized labor pools because the existence of a large number of similar producers provides workers an incentive to invest in industry-specific skills (Marshall, 1890; Rotemberg and Saloner, 2000). The second is easier access to specialized suppliers that, much like specialized workers, are more likely to invest in specialized equipment and services if the existence of a considerable number of similar producers creates the conditions for their growth and survival (Marshall, 1890).

While the literatures on markets-as-networks and agglomerations formulate these arguments at the firm level, their logic should apply also to our analysis of communities. Consider a community with a strong presence in a relatively new industry such as for example biotechnology. Through its producers this community should benefit from the existence of other communities with a strong presence in biotech because the existence of such communities implies greater availability of valuable information - such as information regarding dead ends and promising directions in drug development or methods to speed up the drug development 
processes - but also a deeper pool of workers with the ideal mix of skills sought by producers in this industry and a deeper pool of specialized suppliers.

Importantly, the literature on agglomerations goes beyond merely pointing to the beneficial side of similarity. It also suggests that these benefits are strengthened by propinquity. Careful analyses of the diffusion of information (Jaffe, 1989; Jaffe et al., 1993; Almeida and Kogut, 1999; Singh, 2005; Agrawal, Kapur, and McHale, 2008) suggest that information flows more readily when similar producers are located near each other in geographical space. Three related information channels account for the link between propinquity and information circulation: the greater movement of skilled workers among geographically proximate firms than among firms located far from each (Saxenian, 1994; Almeida and Kogut, 1999; Rosenkopf and Almeida, 2003); the greater propensity of firms to form ties with firms that are located near them than with firms residing in distant locales (Lincoln, Gerlach, and Takahashi, 1992; Kono et al., 1998; Sorenson and Stuart, 2001; Marquis, 2003); and the greater probability of inter-personal ties among geographically proximate individuals (Bossard, 1932; Festinger, Schachter and Back, 1950; Singh, 2005).

Propinquity is also thought to strengthen the benefits arising from access to skilled workers and specialized suppliers. Research on the geographical mobility of workers and entrepreneurs suggests that it may be easier to poach skilled workers from similar producers located nearby than from similar producers located elsewhere because workers generally prefer to move to employers residing in closer locations (Figueiredo, Guimaraes, and Woodward, 2002; Dahl and Sorenson, 2010). At the same time, it may be easier for specialized suppliers to engage in market transactions with buyers located nearby because the non-routine and unstandardized 
nature of the transactions they carry out typically requires frequent face-to-face interactions that are facilitated by propinquity (Storper and Christopherson, 1987; Romo and Schwarz, 1995).

Based on these literatures, we suggest that the mutualistic effects of similarly positioned communities will be strongest among those communities located near each other in geographic space. The competitive effect of similarity, by contrast, should be less dependent on geographical proximity because competition in national markets is not influenced by propinquity. Communities that occupy similar market niches experience the harmful effects of this overlap as their constituent firms seek to place the same kinds of goods in the market, irrespective of where they are located in geographic space.

To summarize the implications of our argument, imagine two communities that occupy similar market niches and that are located near each other in geographic space. While these two communities would experience competition for the placement of their goods, they would also experience mutualism arising from access to valuable information, skilled workers, and specialized suppliers. Through local labor mobility and localized inter-organizational and interpersonal networks, geographic proximity would strengthen the circulation of information regarding technologies, products, and market information among firms residing in these neighboring communities. Geographic proximity would also give easier access to skilled workers and specialized suppliers. Both existing firms and would-be entrepreneurs considering the creation of new firms would have access to these beneficial effects of similarity.

If geographic distance weakens the mutualistic effects of similarity, then communities occupying similarly market niches should find the competitive effect of market similarity prevailing when those communities are far removed in geographic space. In contrast, the 
balance between competitive effects and mutualistic effects should tilt in favor of mutualism when communities with similar market niches are located near each other.

Empirically we test our predictions by examining the community-level impact of niche overlap with adjacent communities (local market niche overlap)— communities that have common geographical boundaries—as distinct from market niche overlap with distant communities (non-local market niche overlap)—communities that do not have common geographical boundaries. Furthermore, in computing the measures of local and non-local market niche overlap, we model geographical proximity not just as a binary measure of local versus nonlocal, but rather as a continuous measure of actual distance between the focal community and all other communities.

To test our predictions, we must identify an appropriate measure of impact as it relates to these communities. The options are several. A substantial body of work has shown that the competitive and mutualistic effects of similarity apply to a range of measurable firm outcomes: mortality rates, founding rates, growth rates, profitability, strategic behaviors, and innovation (Baum and Singh, 1994; Podolny et al., 1996; Ruef, 1997; Ingram and Roberts, 2000; Dobrev et al., 2001; Bothner, 2003; Sorenson and Audia, 2000; Sorensen, 2004; Ingram and Lifschitz, 2006). Thus, in keeping with our earlier conceptualization of communities as aggregates of firms as well as our theoretical emphasis on firms as social units with significant exposure to both the competitive and mutualistic effects posited by the theory, we seek evidence of a community's economic activity by examining firm exits and firm foundings.

We therefore formulate the following hypotheses: 
Hypothesis 1: The greater a community's non-local market niche overlap, the greater the rate of firm exits and the lower the rate of firm foundings within a community

Hypothesis 2: A community's local market niche overlap will have a less detrimental effect on a community's firm foundings and firm exits than a community's non-local market niche overlap.

Our argument does not offer a clear prediction as to whether the mutualistic effects arising from geographical proximity to similarly positioned communities will outweigh the competitive effects. For this reason, we avoid making a specific prediction regarding any positive net effect that local market niche overlap might have on community's firm foundings and firm exits. We instead limit ourselves simply to exploring this possibility.

\section{DATA AND METHODS}

To empirically examine competition among communities we had to make two important methodological choices: 1) the choice of communities' constituent firms on which to focus to create measures of niche overlap and 2) the geographical boundaries of the urban system within which competitive relations are examined. Regarding the first step, the analysis should concentrate on those industries that ship their outputs beyond the community's boundaries which are also known as basic production activities (Alexander, 1954; see also: Duncan et al., 1960: p. 33; Scott, 1998: 51-53). Non-basic production activities consist of support industries that produce goods and services primarily for local, intra-community consumption. Manufacturing industries are an ideal choice for the study of competition among communities because they generally ship their outputs beyond the boundaries of the communities in which they reside. 
This means that manufacturing firms residing in different locales compete against each other for the same opportunities of exchange. Service industries, in contrast, include a mix of basic and non-basic activities and thus introduce potentially extraneous influences in any measure of niche overlap (Duncan et al., 1960: 56-58). ${ }^{3}$ So, as an initial step toward an analysis of community competition and following the approach taken in other analysis of regions and cities (Meyer, 1986; Scott, 1998), in this study we chose to focus the analysis on manufacturing industries.

Drawing the geographical boundaries of the urban system requires considering the strength of the competitive interactions among communities stemming from the commercial activities of their manufacturing firms. If one would argue that U.S. communities' constituent firms competed as intensely against other U.S. communities' constituent firms as they did against the constituent firms of communities outside the U.S., then a logical step would be to conduct a global analysis of competitive interactions among communities. Between 1976 and 1988, the period of this study, however, foreign exports accounted for a relatively small share of total output. Bernard and Jensen (1995), in a detailed analysis of the foreign export activities of U.S. manufacturers between 1976 and 1987, report that foreign exports as a share of manufacturing rose from about $4 \%$ in 1963 to $9 \%$ in 1988 . Furthermore, only $14.6 \%$ of all establishments engaged in foreign export activities and, perhaps even more revealing of the modest impact of foreign exports on U.S. manufacturing, $71.1 \%$ of these exporting establishments exported less than $10 \%$ of total shipments. Thus given the modest weight of foreign exports, in this study we chose to test our theory by examining competition among U.S. communities.

\footnotetext{
${ }^{3}$ The problem of separating service industries oriented toward the local market and service industries oriented toward the national market is particularly pronounced in our study because we use establishments data at the level of two-digit Standard Industrial Classification (SIC) sectors. Lower level of aggregations may allow inclusion of service industries without compromising the validity of the inferences.
} 
The dataset we use was assembled by the U.S. Small Business Association (SBA) and contains information on U.S. establishments in all two-digit nongovernmental Standard Industrial Classification (SIC) sectors between 1976 and 1988. To determine the geographical boundaries of communities we use the 1980 classification of Labor Market Areas (LMAs), territorial units defined by the U.S. Census on the basis of journey-to-work patterns. With a median land area of 4,638 square miles, LMAs are considerably larger than the 3,000-plus U.S. counties, another commonly used unit of analysis, which have a median land area of 622 square miles. However, to focus on counties would be to fracture the major metropolitan regions that frequently contain multiple counties into spuriously independent sections. LMAs overlap to a large extent with Metropolitan Statistical Areas (MSAs). The only difference in the 1980 classification is that, unlike MSAs, LMAs are not required to contain a metropolitan area with at least one urbanized area of 50,000 people. So LMAs include rural locales and allow us complete coverage of the geographic space in the U.S. Our analyses include all 380 LMAs within the contiguous United States (i.e. Hawaii and Alaska are excluded).

The Small Business Association dataset with which we conduct these analyses is based on Dun and Bradstreet's Dun's Market Identifiers files. These files assign a unique numerical identifier to every U.S. establishment in existence as of December of every even-numbered year from 1976 through 1988. "Establishments" are defined as single physical locations at which business activity is conducted; they are identified by combining information collected by Dun and Bradstreet's credit-reporting function with information collected by other organizations that compile lists of companies. The structure of these data enables us to identify establishment openings and closings by comparing data from two consecutive years. Furthermore, the SBA dataset also differentiates establishments as being either autonomous establishments or branch 
operations of existing businesses. We include both autonomous establishments and branches when we compute a community's market niche because both types of establishments target market resources such as customers and both generate information that may be of value to similar producers. The dependent variables are foundings and exits of autonomous establishments, hereafter called firm foundings and firm exits. These are based only on autonomous establishments and exclude branches. The reason is that branch openings and closings often reflect decisions made by corporate executives in distant locales, which may be less affected by the competitive and mutualistic processes that are the focus of our analysis. The data incorporate firm foundings and exits between 1976 and 1978 (which we date 1978), and so on for 1978, 1980, 1982, 1984, 1986, and 1988. Thus, we have six two-year waves of observations for the United States.

Given that our data cover all LMAs within the contiguous United States, we can model both the effects of geographic proximity and the effects of similarity in market niche on firm foundings and exits. That is, we can separately consider the effects of a focal LMA's market niche overlap with adjacent as well as distant LMAs. As we noted above, adjacent LMAs are those that share a common border. By disaggregating local market niche overlap from non-local overlap, we are able to tease apart the potentially different competitive effects of geographically proximate versus geographically distant communities.

Independent Variables

Our measure of market niche overlap captures the extent to which the focal LMA resembles other LMAs with regards to the distribution of manufacturing establishments. As we noted above, these include both autonomous establishments and branches. For each LMA, we 
calculate the proportion of establishments in the 20 manufacturing-related SIC codes (numbers 20-39) to total manufacturing establishments in that $\mathrm{LMA}^{4}$ :

$$
p_{i k}=\frac{n_{i k}}{N_{i}}
$$

where $i$ indexes the 380 LMAs, $k$ indexes the 20 manufacturing SICs, $n_{i k}$ is the count of establishments in the $k^{\text {th }}$ SIC in the $i^{\text {th }}$ LMA, and $N_{i}$ is the total number of manufacturing establishments in the $i^{\text {th }} \mathrm{LMA}$.

With these proportions, we compute the Euclidean distance for every pair of communities as follows:

$$
d_{i j}=\sqrt{\sum_{k}\left(p_{i k}-p_{j k}\right)^{2}}
$$

where $i$ and $\mathrm{j}$ index the $380 \mathrm{LMAs}, p_{i k}$ is the proportion of establishments inthe $k^{\text {th }}$ SIC in the $i^{\text {th }}$ LMA, $p_{i k}$ is the proportion of establishments inthe $k^{\text {th }}$ SIC in the $j^{\text {th }}$ LMA, and $i \neq j$. High distance scores indicate dissimilarity in terms of the industrial profile in each of the communities.

(Tables 1 and 2 about here)

To illustrate how these proportions represent the industry profile for a given community and how such measures allow us to situate communities in market space, we take a closer look at the industrial profile of six specific communities (see Table 1). We include four of the largest U.S. cities in terms of human population - Los Angeles, New York, Chicago, and Boston - and two cities broadly representatives of locales that occupy more peripheral positions in the urban system - Bakersfield, California; and Dickinson, North Dakota. Turning first to New York City, we see strong representation of a broad array of manufacturing fields. While the largest proportions of establishments are seen in apparel and textile products, New York's profile also

\footnotetext{
${ }^{4}$ Duncan et al. (1960) used the same approach to describe the industrial profiles of large U.S. cities and also to examine whether cities of similar size have similar industrial profiles.
} 
features substantial activity in paper and allied products, electronic and other electric equipment, instruments and related products, and miscellaneous manufacturing industries.

Like New York, Los Angeles, Chicago and Boston all have differentiated industrial profiles, although each one features a different industry in its largest proportion. However, unlike New York, these three urban centers have lesser representation in traditional industries such as textile and apparel, which appear to be more pronounced in New York. Chicago's strongest presence is in fabricated metal products. Boston leads in the manufacture of instruments and electronic equipment. And Los Angeles, like Boston, has strong representation in electronic equipment, although with a large proportion also in the manufacturing of transportation equipment. Consequently, Los Angeles, Chicago and Boston reflect differentiation of a sort distinct from that of New York, by virtue of their less traditional manufacturing bases.

On the other hand, Bakersfield (a southern California city of roughly 250,000) and Dickinson (a North Dakota city of roughly 170,000) are more similar to each other than to the four urban centers. Both have a strong presence in food products and petroleum, two industries that have little or no representation in the four urban centers. And both have weaker representation in electronics and instruments, two industries that are more pronounced in the four urban centers.

Given these descriptions, one would expect low overlap between these smaller cities and the four major urban centers, but high overlap among the urban centers and among the smaller cities. Such an intuition plays out in the data albeit with some nuance, as can be seen in Table 2 which reports the market distances among the six U.S. communities discussed above. The smallest distance score, indicating a high level of market niche overlap, occurs between Bakersfield and Dickinson: 0.09. In contrast, Dickinson shows far less overlap with the four 
urban centers as seen in distance scores that range from 0.23 and 0.43 . Among three of the urban centers - Los Angeles, Chicago, and Boston - we see distance scores ranging between 0.13 and 0.19, indicating a high degree of similarity in their manufacturing sectors. However, all three show greater distance from New York with scores ranging from 0.29 to 0.35 , a finding that reflects our prior examination of the manufacturing proportions.

(Figure 1 about here)

We use classic multidimensional scaling (MDS; Kruskal and Wish, 1978) to plot the market niches of these communities in two-dimensional space (for similar applications see: Burt and Carlton, 1989; Stuart and Podolny, 1996). In classic multidimensional scaling, the dimensions used for graphical representation are equivalent to the factors extracted in a principal component analysis. We use the two largest components to define the axes of the graph. The horizontal axis captures high loadings in industries such as instruments, electronic equipment, fabricated metal, and rubber, whereas the vertical axis captures high loadings on industries such as textile, apparel, furniture, and paper products. Two communities appear close together in the graph to the extent that they have similar patterns of ties to those two industry groups. The graph (see Figure 1) shows clear differentiation between Dickinson, the community displaying the most focused manufacturing profile in this set and situated in the southwest corner of the graph, and the group of Los Angeles, Chicago, and Boston, each displaying a more differentiated manufacturing profile and clustered in the northeast corner of the graph. Bakersfield and New York are positioned in the central section as a function of their intermediate profiles. At the same time, communities that have similar patterns of ties to particular industries—such as Boston, Los Angeles, and Chicago situated in the eastern half of the graph and Bakersfield and 
Dickinson in the west and the center graph —are adjacent in the map. New York, with its unique profile, occupies a relatively isolated niche in the north central section.

The next step in the computation of the market niche overlap variables is to obtain market

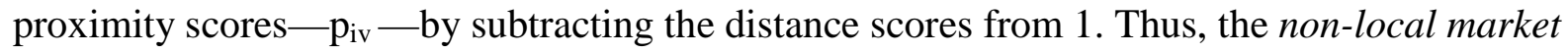
niche overlap (NLMNO) for a focal LMA is the average of the proximity scores between that LMA and the LMAs not adjacent to it. Because non-adjacent LMAs vary greatly in their geographic distances from the focal LMA, we weigh each proximity score by the geographic distance between the focal LMA and the non-adjacent LMA. Taking as the center of each LMA the center of its most populous county, we use the coordinates of these center points to compute the geographical distance between all possible pairs of LMAs. Formally:

$$
\operatorname{NLMNO}_{i}=\left(\sum_{i v} \frac{p_{i v}}{g_{i v}}\right) / n a_{i}
$$

where $i$ indexes the 380 LMAs, $v$ indexes those LMAs not adjacent to the $\mathrm{i}^{\text {th }}$ LMA, $\mathrm{p}_{\mathrm{iv}}$ is the market proximity between communities $i$ and $\mathrm{v}, \mathrm{g}_{\mathrm{iv}}$ is the geographic distance between communities $i$ and $v, n a_{\mathrm{i}}$ is the count of LMAs that are not adjacent to LMA $i$, and $i \neq v$. To compute local market niche overlap (LMNO) we average the market proximity scores between the focal LMA and the adjacent LMAs, again weighting each score by the geographic distance between the adjacent LMA and the focal LMA. Formally:

$$
L M N O_{i}=\left(\sum_{i z} \frac{p_{i z}}{g_{i z}}\right) / a_{i}
$$

where $i$ indexes the 380 LMAs, $z$ indexes those LMAs adjacent to the $i^{\text {th }}$ LMA, $p_{\mathrm{iz}}$ is the market proximity between communities $i$ and $z, g_{i z}$ is the geographic distance between communities $i$ and $z, a_{i}$ is the count of LMAs adjacent to LMA $i$, and $i \neq z$. Preliminary analyses available from the authors upon request did not yield evidence of of curvilinear effects of the overlap 
variables. However, when we used both the untransformed and log transformations of the overlap variables, we found that the log transformations yielded a better model fit. These preliminary analyses therefore suggested nonlinear relationships between the market niche overlap variables and the dependent variables such that additional increments in the niche overlap variables have a declining impact on firm foundings and exits. Presumably, this occurs because at high levels of similarity the balance between mutualistic and competitive effects shifts. Below we report analyses in which we use the log transformations.

To illustrate how local and non-local overlap measures vary across communities, we return to the examples of Los Angeles and New York which reveal a striking difference in their local overlaps. Los Angeles has a relatively low local niche overlap (LMNO X $100=0.7$ ) as compared to the rest of the country (average LMNO X $100=1.3$ ), and New York has a relatively high local niche overlap (LMNO X $100=2.8$ ). In other words, Los Angeles does not strongly resemble its neighboring communities whereas New York does.

An inspection of the communities surrounding each locale provides ready insight. San Diego and Santa Barbara - two California communities situated to the south and to the north of Los Angeles, respectively - show differentiated profiles similar to that of Los Angeles. Yuma, Arizona, and Las Vegas, Nevada - both to the east of Los Angeles - and Bakersfield, California - to the north of Los Angeles - however, have narrower industrial profiles and strong representation in industries that have little or no presence in Los Angeles including food, chemical, and stone and clay. New York's neighbors, on the other hand, are Port Jervis, New York; Trenton, New Jersey: Westchester, New York; and Hartford, Connecticut. These communities look a lot like New York, possessing significant manufacturing activity in both more traditional industries such as apparel and lumber and in less traditional industries such as 
industrial machinery, fabricated metals, and chemicals. The slight differences among these LMAs are that fabricated metals and industrial machinery have a strong presence in Hartford, CT, whereas the chemical industry is heavily represented in Trenton. In short, whereas New York and its neighboring LMAs are all involved in similar manufacturing activities, Los Angeles and its neighbors are not.

Because the effects of geographic proximity and of market niche overlap discussed above may be attributable to other dynamics, we include several control variables in our models. Market niche overlap may reflect in part the width of the market niche occupied by a community. That is, overlap may simply be a function of diversification. Organizational ecologists refer to such diversification as niche width (Freeman and Hannan, 1983). Niche width may confound the analysis if, for example, a broad market niche tends to have greater overlaps with the market niches of other locales. To create a measure of market niche width (MNW) we compute a Herfindahl index of the degree of industry concentration. This measure takes a value of one if a community is concentrated in a single manufacturing sector and tends towards zero as diversity increases. We base our calculations on the proportion of a focal LMA's establishments in a specific manufacturing SIC relative to the total number of manufacturing establishments in that focal LMA. Next, we subtract each LMA's index from one. In this way, higher index values indicate greater diversity and thus occupation of a broader market niche. Formally,

$$
M N W_{i}=1-\left[\sum_{k} p_{i k}^{2}\right]
$$

and

$$
p_{i k}=\frac{n_{i k}}{N_{i}}
$$


where $i$ indexes LMAs, $k$ indexes the 20 SICs under consideration (from 20-39), $n_{i k}$ is the raw count of establishments in the $k^{\text {th }}$ SIC in the $i^{\text {th }}$ LMA, and $N_{i}$ is the total number of manufacturing establishments in the $i^{\text {th }}$ LMA. At the extremes, we see Dalton, GA with a market niche width of .54 and the Port Jervis area of New York, New Jersey and Pennsylvania with a market niche width of .93. Dalton is often referred to as the "Carpet Capital of the World" and is home to the largest relative concentration of textile mill establishments in the nation. Port Jervis, on the other hand, is known mostly as the last stop on the 95-mile commuter line terminating at Hoboken, New Jersey and New York City.

In addition to the potential confounding effects of niche width, communities may also experience varying levels of firm foundings and exits as a result of different rates of growth in the industries they host. We control for this potential confounding by including a variable that records the growth of the industries present in a community in a given year. The industry mix growth is the average of the employment growth in all manufacturing industries weighted by the proportion of those industries in the community; an industry that is not represented in the community has a proportion of zero and therefore contributes zero to this variable. Foundings and exits at the LMA level in some cases may also reflect historical trajectories that affected larger territorial units such as groupings of adjacent LMAs. To take into account such potential influences, we control for the count of firm foundings and firm exits in adjacent LMAs weighted by the geographical distance to the focal LMA. If firm foundings and exits in a given LMA reflect historical processes taking place in the adjacent LMAs beyond the processes captured by our local market niche overlap variable, then these spatial interdependence variables may help partial out these effects. 
The size of a community and the characteristics of its work force may also factor in to firm foundings and exits. We expect that both firm foundings and firm exits occur in greater numbers in densely populated communities. Thus, human population density, the number of persons per square mile, differentiates between urban centers and rural locales. We also include two composite indicators based on U.S. Census information: a community’s skilled work force is a composite of post-graduate degrees per 1,000 square miles, professional and technical employees per 1,000 square miles, patents granted per 1,000 square miles, and doctorates granted per 1,000 square miles (reliability =.99); a community's personal wealth is a composite of personal income per capita, income per household, and dividend, interest, and rent per capita (reliability =.99). Finally, we control for the cost of manufacturing by including in the models average wage for all manufacturing jobs in the LMA and for income inequality by including wage dispersion across the industries present in the community. Descriptive statistics for all variables are reported in Table 3.

(Tables 3 and 4 about here)

Both dependent variables, firm foundings and firm exits, are event-count variables that take only non-negative results and show over-dispersion. To deal with this over-dispersion, we use a negative binomial specification. In addition, we include LMA-fixed effects to control for a wide range of LMA characteristics that might influence manufacturing foundings and exits including local cultural beliefs, natural advantages such as climate, proximity to harbors, and mineral deposits, and service industry agglomerations (e.g., financial services, tourism) that may constrain manufacturing activities.

\section{RESULTS}


Table 4 reports the results of our analyses. Beginning with the analyses of firm foundings, Model 1 shows several significant effects for the control variables. Perhaps unsurprisingly larger skilled work forces, higher rates of industry growth, and greater residents' wealth are positively and significantly associated with higher foundings. Population density, niche width, and firm foundings in adjacent LMAs, however, are not significantly associated with firm foundings. Interestingly, the positive and significant coefficient of average wage does not support the view that lower input costs encourage firm foundings. Turning to the effects of the independent variables, the results in Model 2 indicate that greater non-local niche overlap suppresses firm foundings. On the other hand, greater local niche overlap increases firm foundings. So although we were unable to say a priori whether the stronger mutualism arising from geographical proximity to similarly positioned communities would outweigh the competitive effect, the results suggests that for geographically proximate communities the mutualistic effect of market similarity outweighs the competitive effect of market similarity to the point of generating net beneficial effects of local market niche overlap.

Turning to the analyses of firm exits, we find again in Model 3 several significant coefficients for the control variables. Greater population density, larger skilled work forces, higher average wages, higher rates of industry growth, and firm exits in adjacent LMAs are all positively and significantly associated with higher exits. Niche width continues to have a negligible effect and greater residents' wealth, which is positively and significantly associated with firm foundings, does not significantly affect firm exits. In Model 4, local niche overlap and non-local niche overlap have opposing effects that are in line with our argument. Greater nonlocal niche overlap increases firm exits whereas greater local niche overlap suppresses firm exits. Together the results support our hypotheses. Non-local niche overlap increases firm exits and 
decreases firm foundings, as specified in hypothesis 1 , and the effects of local niche overlap on firm exits and firm foundings are less detrimental than the effects of non-local niche overlap, as predicted in hypothesis 2. So geography conditions the impact of niche overlap on both firm foundings and exits. At the mean value of nonlocal market niche overlap, a standard deviation increase corresponds to a $14 \%$ decline in foundings and a $4 \%$ increase in exits, whereas, at the mean value of local market niche overlap, a standard deviation increase implies a $25 \%$ increase in foundings and a $3 \%$ decline in exits.

\section{CONCLUSIONS}

By applying the ecological concept of the niche to local communities, this study provides new opportunities for organizational ecologists to advance the study of inter-community relations. Research on communities recognizes the importance of social relations as a constitutive element of community structure but it emphasizes largely relations within, rather than across, communities (Fleming, King, and Juda, 2007; Ingram and Lifschitz, 2006; Audia and Teckchandani, 2010). At the meantime, there is an increasing need to understand the implications of viewing places as nodes in networks. Much of the literature on inter-community relations focuses on relations that arise in physical space (Hedstrom, 1994; Greve, 2002) or in social topologies such as power structures (Alderson and Beckfield, 2004) and corporate elite networks (Palmer and Friedland, 1987), but only limited attention has been focused on market relations (Audia et al., 2006; Whittington et al., 2009). Our empirical analysis extends the emerging literature on inter-community relations by showing that the niches that communities occupy in market space have concrete economic consequences. Specifically, occupying market niches crowded with geographically distant communities suppresses firm foundings and 
increases firm exits, but occupying market niches crowded with geographically proximate communities increases firm foundings and decreases firm exits.

Besides contributing to the literature on communities, these findings extend ecological analysis of the organization's niche. Ecologists recognize that occupying a crowded niche may have both competitive and mutualistic effects (Hannan, Polos, and Carroll, 2007). Mutualistic effects, however, are thought to arise primarily in situations in which social actors occupying the same niche lack legitimacy. When legitimacy is acquired, larger numbers of similar others are viewed as having primarily competitive effects. Our integration of insights from ecological theory and the literatures on social networks and agglomeration contributes to niche theory by suggesting (1) that mutualism among actors occupying the same niche may also stem from access to a broader range of resources associated to the existence of similar others such as valuable information, skilled workers, and specialized assets and (2) that access to such resources is magnified by physical proximity. As much ecological research on legitimacy and as much research on agglomerations, a limitation of our findings is that the do not allow us to isolate mechanisms underlying mutualistic relations among geographically proximate communities. We can only say that the mechanisms we identified are likely to account for the mutualistic effects evidenced by our findings.

Although we deliberately chose to emphasize inter-community relations in this study, we view both internally focused and externally focused approaches to the study of communities as important for enriching the organizational perspective on communities. Internal attributes of communities such as social network configurations (Fleming, King, and Juda, 2007) and cultural beliefs (Lounsbury, 2007; Marquis et al., 2007) may help explain the diverging economic and institutional trajectories of communities. At the same time, inter-community relations may also 
influence internal processes as shown in studies of diffusion (Strang and Soule, 1998) and community abandonment (Bluestone and Harrison, 1982), among others. We think that exciting opportunities to expand research on communities may lie in considering the interplay of external and internal processes.

(Figure 2 about here)

In that spirit, one extension of our approach to the study of market niches would be a study of changes in the market niches of communities and potential causes of those changes. Figure 2, based on multidimensional scaling of the pooled data for 1976 and 1986, offers a glimpse of such dynamics. As one would expect, the market niches of communities are not so fluid as to move from one side of the map to the other, but these niches do shift over time. Chicago and Los Angeles experienced the least movement. Bakersfield shows the greatest, shifting in the same direction as New York and Boston. None of these communities moves north, a direction that would indicate a greater representation of industries such as textiles, apparel, and leather. What causes the distance and the direction of these movements? Why are some communities more fluid than others? One possible approach to tackling these questions is to view processes internal to communities as factors that influence inter-community relations. Internal community features such as norms, cultural beliefs and social network configurations that have been shown to alter the trajectories of communities (Saxenian, 1994; Fleming et al., 2007; Lounsbury, 2007; Marquis et al., 2007; Freeman and Audia, 2011) might be useful starting points for examining variations in the extent to which communities change their niche in the market and the directions they take.

A second direction for future research is to examine factors other than propinquity that create social structures that overlay market relations. Board interlocks, for example, structure 
social relations among corporate elites and serve as mechanisms for information transfer (Davis and Greve, 1997). Although they are especially likely between companies headquartered close together, they also link distant places. One could extend our analysis of the interaction between niches in market space and locations in geographic space by considering communities’ positions in the board interlock structure. Intra-corporate networks (Ingram and Baum, 1997) and air travel linkages (Marquis, 2003) are other possible mechanisms that influence social interactions and information flows among communities.

Our findings also speak to the literature on agglomerations. Scholars of agglomerations tout the benefits of industrial specialization, suggesting that local competition and withinindustry transmission of ideas amplify the externalities arising from localized information flows (e.g., Rosenthal and Strange, 2004). Our findings suggest that the benefits of co-location may generalize beyond the cases of communities that specialize in a particular industry, showing that geographically proximate communities that engage in similar activities benefit from being close to each other regardless of whether their industrial profiles are specialized or differentiated. Therefore, we can speculate that similarity, independent from specialization, may be sufficient to yield the benefits of proximity in geographic space.

In conclusion, our analysis of inter-community relations arising in the market extends the limited research that focuses on external processes affecting community outcomes and, we think, offers a wealth of opportunities for future research on the interplay of processes internal to communities and processes external to them. 


\section{REFERENCES}

Agrawal, A., D. Kapur and J. McHale (2008), 'How do spatial and social proximity influence knowledge flows?' Journal of Urban Economics, 64, 258-269.

Alderson, A.S. and J. Beckfield (2004), 'Power and position in the world city system.' American Journal of Sociology, 109, 811-51.

Aldrich, H.E. and M. Ruef (2006), Organizations Evolving, $2^{\text {nd }}$ ed. Sage: London.

Alexander, J. (1954), 'The basic-nonbasic concept of urban economic function,' Economic Geography, 30, 246-261.

Almeida, P. and B. Kogut (1999), 'Localization of knowledge and the mobility of engineers in regional networks,' Management Science, 45, 905-917.

Altshuler, A. A. and D. E. Luberoff (2003), Mega-Projects: The Changing Politics of Urban Public Investment. Brookings Institution Press.

Audia, P.G., J.H. Freeman and P. D. Reynolds (2006), 'Organizational foundings in community context: instruments manufacturers and their interrelationship with other organizations,' Administrative Science Quarterly, 51, 381-419.

Audia, P.G. and C.I. Rider (2010). 'Close, but not the same: locally headquartered organizations and agglomeration economies in a declining industry,' Research Policy, 39, 360-374.

Audia, P.G. and A. Teckchandani (2010), 'The effect of connected and isolated voluntary associations on economic activity in the U.S., 1984-2000,' Social Science Research, 39, 1153-1163.

Barnett, W.P. and M. Woywode (2006). 'From red Vienna to the Anschluss: ideological competition among Viennese newspapers during the rise of national socialism,' American Journal of Sociology, 109, 1452-1500. 
Baum, J.A.C. and J.V. Singh (1994), 'Organizational niche overlap and the dynamics of organizational founding,' Organization Science, 5, 483-501

Bernard, A. B. and J.B. Jensen (1995), 'Exports, jobs, and wages in U.S. manufacturing: 19761987.' Brookings Papers on Economic Activity. Microeconomics, 67-112

Bluestone, B. and B. Harrison (1982), The Deindustrialization of America: Plant Closings, Community Abandonment, and the Dismantling of Basic Industry. Basic Books: New York:

Bossard, J.H. S. (1932), 'Residential propinquity as a factor in marriage selection,' American Journal of Sociology, 38, 219-224.

Bothner, M. S. (2003), 'Competition and social influence: The diffusion of the sixth-generation processor in the global computing industry,' American Journal of Sociology, 108, 11751210.

Burt, R. S. (1987), 'Social contagion and innovation: Cohesion versus structural equivalence,' American Journal of Sociology, 92, 1287-1335.

Burt, R. S. (1992), Structural Holes: The Social Structure of Competition. Harvard University Press: Cambridge, MA.

Burt, R.S. and D. S. Carlton (1989), 'Another look at the network boundaries of American markets,' American Journal of Sociology, 94, 723-753.

Carroll, G.R. (1985), 'Concentration and specialization: dynamics of niche width in populations of organizations,' American Journal of Sociology, 90, 1262-1283.

Carroll, G.R. and A. Swaminathan (2000), 'Why the microbrewery movement? Organizational dynamics of resource partitioning in the U.S. brewing industry,' American Journal of Sociology, 106, 715-762. 
Carroll, G.R. and J. Wade (1991), 'Density dependence in the organizational evolution of the American brewing industry across different levels of analysis,' Social Science Research, 20, 271-302.

Chung, W. and J. Alcacer (2002), 'Knowledge seeking and location choice of foreign direct investment in the United States,' Management Science, 48, 1534-1554.

Dahl, M.S. and O. Sorenson (2010), 'The migration of technical workers,' Journal of Urban Economics, 67, 33-45.

Davis, G.F. and H.R. Greve (1997), 'Corporate elite networks and governance changes in 1980s,' American Journal of Sociology, 103, 1-37.

Dietzenbacher, E. and M. L. Lahr (2001), 'Introduction.' in M. L. Lahr and E. Dietzenbacher, (eds), Input-Output Analysis: Frontiers and Externsions. Palgrave: New York.

DiMaggio P. J. (1986), 'Structural analysis of organizational fields: A blockmodel approach,' in B.M. Staw and L. Cummings (eds.), Research in Organizational Behavior. JAI Press: Greenwich, CT.

Dobrev, S., T.-Y. Kim and M. T. Hannan (2001), 'Dynamics of niche width and resource partitioning,' American Journal of Sociology, 106, 1299-1337.

Duncan, O.D., W. R. Scott, S. Lieberson, B. Duncan and H. H. Winsborough (1960), Metropolis and Region. The John Hopkins Press: Baltimore, MD.

Elton, C. (1925), Animal Ecology. Sidgwick and Jackson: London.

Festinger, L., S. Schachter and K. W. Back (1950), Social Pressures in Informal Groups: A Study of Human Factors in Housing. Harper: New York.

Figuereido, O., P. Guimaraes and D. Woodward (2002), 'Home-field advantage: location decisions of Portuguese entrepreneurs,' Journal of Urban Economics, 52, 341-361. 
Fleming, L., C. King, III and A. Juda (2007), 'Small worlds and regional innovation,' Organization Science, 18, 938-954.

Freeman, J. H. and P. G. Audia (2006), 'Community ecology and the sociology of organizations,' Annual Review of Sociology, 32, 145-169.

Freeman, J.H. and P.G. Audia (2011), 'Community context and founding processes of banking organizations,' Research in the Sociology of Organizations, 33.

Freeman, J.H. and M. T. Hannan (1983), 'Niche width and the dynamics of organizational populations,' American Journal of Sociology, 88, 1116-1145.

Glaeser, E., H.D., Kallal, J.A., Scheinkman and A. Shleifer (1992), 'Growth in cities,' Journal of Political Economy, 100, 1126-1152.

Gray, V. and D. Lowery (1996), 'A niche theory of interest representation,' The Journal of Politics, 58, 91-111.

Greve, H.R. (2002), 'An ecological theory of spatial evolution: local density dependence iun Tokyo banking,' Social Forces, 80, 47-880.

Hannan, M.T., G.R. Carroll and L. Polos (2003), 'The organizational niche,' Sociological Theory, 21, 309-340.

Hannan, M.T. and J.H. Freeman (1977), 'The population ecology of organizations,' American Journal of Sociology, 82, 929-964.

Hannan, M.T. and J.H.Freeman (1989), Organizational Ecology. Harvard University Press: Cambridge, Mass.

Hannan, M.T., L. Polos and G.R.Carroll (2007), Logics of Organization Theory. Princeton University Press: Princeton, NJ. 
Hedstrom, P. (1994), 'Contagious collectivities: on the spatial diffusion of Swedish trade unions,' American Journal of Sociology, 99, 1157-1179.

Hutchinson, G.E. (1957), 'Some concluding remarks,' Cold Spring Harbor Symposium on Quantitative Biology, 22, 415-427.

Ingram, P., J. and A.C. Baum (1997), 'Chain affiliation and the failure of Manhattan hotels 18981980,' Administrative Science Quarterly, 42, 68-102.

Ingram, P. and C. Inman (1996), 'Institutions, intergroup competition, and the evolution of hotel populations around Niagara Falls,' Administrative Science Quarterly, 41, 629-658.

Ingram, P. and A. Lifschitz (2006), 'Kinship in the shadow of the corporation: the inter-builder network in Clyde river shipbuilding 1711-1990,' American Sociological Review, 71, 334352.

Ingram, P. and P. Roberts (2000), 'Friendships among competitors in the Sydney hotel industry,' American Journal of Sociology, 106, 387-423.

Ingram, P. and H. Rao (2004), 'Store wars: the enactment and repeal of anti-chain store legislation in America,' American Journal of Sociology, 110, 446-487.

Ingram, P. and T. Simons (2000), 'State formation, ideological competition, and the ecology of Israeli's workers' cooperatives, 1920-1992,' Administrative Science Quarterly, 45, 25-53.

Jaffe, A.B. (1989), 'Real effects of academic research,' American Economic Review, 79, 957-970.

Jaffe, A. B., M. Trajtenberg and R. Henderson (1993), 'Geographic localization of knowledge spillovers as evidenced by patent citations.' Quarterly Journal of Economics, 79, 957970.

Klepper, S. (2002), 'The capabilities of new firms and the evolution of the U.S. automobile industry,' Industrial and Corporate Change, 4, 645-666. 
Kono, C., D. Palmer, R. Friedland and M. Zafonte (1998), 'Lost in space: The geography of corporate interlocking directorates,' American Journal of Sociology, 103, 863-911.

Krugman, P. (1991), Geography and Trade. The MIT Press: Cambridge, MA.

Kruskal, J.B. and M. Wish (1978), Multidimensional Scaling. Sage: London.

Lincoln, J. R., M. Gerlach and P. Takahashi (1992), 'Keiretsu networks in the Japanese economy: A dyad analysis of intercorporate ties,' American Sociological Review, 57, 561-585.

Lomi, A. (1995). 'The population ecology of organizational founding: location dependence and unobserved heterogeneity,' Administrative Science Quarterly, 40, 111-144.

Lounsbury, M. (2007), 'A tale of two cities: competing logics and practice variation in the professionalizing of mutual funds,' Academy of Management Journal, 50, 289-307.

Mark, N.P. (1998). 'Birds of a feather sing together.' Social Forces, 77, 435-485.

Markusen, A. (1994), 'Studying regions by studying firms,' Professional Geographer, 46, 477490.

Marquis, C. (2003), 'The pressure of the past: Network imprinting in intercorporate communities,' Administrative Science Quarterly, 48, 655-689.

Marquis, C., M.A. Glynn and G.F. Davis (2007), 'Community isomorphism and corporate social action,' Academy of Management Review, 32, 925-945.

Marquis, C. and M. Lounsbury (2007), 'Vive la resistance: Competing logics and the consolidation of U.S. community banking,' Academy of Management Journal, 50, 799820.

Marshall, A. 1890. Principles of Economics. London: Macmillan.

Martin, P. and C.A. Rogers (1995), 'Industrial location and public infrastructure,' Journal of International Economics, 39, 335-351. 
Marx, M., D. Strumsky and L. Fleming (2009), 'Mobility, skills, and the Michigan non-compete experiment,' Management Science, 55, 875-889.

McKendrick, D.G., J. Jaffee, G.R. Carroll, and O.M. Kessina (2003). 'In the bud? Analysis of disk array producers as a (possibly) emergent organizational form,' Administrative Science Quarterly, 48, 60-94.

McPherson, M. (1983), 'An ecology of affiliation,' American Sociological Review, 48, 519-532.

Meyer, D. R. (1986), 'The rise of the industrial metropolis,' Social Forces, 90, 731-752.

Palmer, D.A. and R Friedland (1987), 'Corporation, class, and city System,' in M. Mizruchi and M. Schwartz (eds), Intercorporate Relations. Cambridge, UK: Cambridge University Press.

Podolny, J.M. and T.E. Stuart (1995). 'A role-based ecology of technological change,' American Journal of Sociology, 100, 1224-1260.

Podolny, J.M., T.E. Stuart and M.T. Hannan (1996), 'Networks, knowledge, and niches: competition in the worldwide semiconductor industry 1984-1991,' American Journal of Sociology, 102, 659-89.

Popielarz, P.A. and J.M. McPherson (1995). 'On the edge or in between: niche position, niche overlap, and the duration of voluntary memberships.' American Journal of Sociology, 101, 698-720.

Porac, J., F. H. Thomas, F. Wilson, D. Paton and A. Kanfer (1995), 'Rivalry and the industry model of Scottish knitwear producers,' Administrative Science Quarterly, 40, 203-227.

Porter, M. E. (2000), 'Location, competition, and economic development: Local clusters in a global economy,' Economic Development Quarterly, 14, 15-34. 
Romo, F. P. and M. Schwartz (1995), 'The structural embeddedness of business decisions: the migration of manufacturing plants in New York state 1960 to 1985,' American Sociological Review, 60, 874-907.

Rosenthal, S.S. and W.C. Strange (2003), 'Geography, industrial organization, and agglomeration,' The Review of Economics and Statistics, 85, 377-393.

Rosenkopf, L. and P. Almeida (2003), 'Overcoming local search through alliances and mobility,' Management Science, 49, 751-766.

Rotenberg, J.J. and G. Saloner (2000). 'Competition and human capital accumulation: a theory of interregional specialization and trade,' Regional Science and Urban Economics, 30, 373404.

Rotolo, T. and J.M. McPherson (2001). 'The system of occupations: modeling occupations in sociodemographic space.' Social Forces, 79, 1095-1130.

Ruef, M. (1997), 'Assessing organizational fitness on a dynamic landscape: an empirical test of the relative inertia thesis,' Strategic Management Journal, 18, 837-853.

Ruef, M. (2000). 'The emergence of organizational forms: a community ecology approach.' American Journal of Sociology, 106, 658-714.

Ruef, M. (2004a), 'The demise of an organizational form: a community ecology approach,' American Journal of Sociology, 109, 1365-1410.

Ruef, M. (2004b), 'For whom the bell tolls: ecological perspectives on industrial decline and resurgence,' Industrial and Coporate Change, 13, 61-89.

Saxenian, A. (1994), Regional Advantage. Harvard University Press: Cambridge, Mass. 
Saxenian, A. (2005), 'From brain drain to brain circulation: transnational communities and regional upgrading in India and China,' Studies of Comparative International Development, 40, 35-61.

Scott, A. W. (1998), Regions and the World Economy. Oxford University Press: Oxford, UK.

Singh, J. (2005), 'Collaborative networks as determinants of knowledge diffusion patterns,' Management Science, 51, 756-770.

Sorensen, J. B. (2004), 'Recruitment-based competition between industries: a community ecology,' Industrial and Corporate Change, 13, 149-170.

Sorenson, O. and P.G. Audia (2000), 'The social structure of entrepreneurial activity: Geographic concentration of footwear production in the Unites States 1940-1989,' American Journal of Sociology, 106, 424-462.

Sorenson, O. and T.E. Stuart (2001), 'Syndication networks and spatial distribution of venture capital investments,' American Journal of Sociology, 106, 1546-1588.

Stuart, T.E. and J. M. Podolny (1996), 'Local search and the evolution of technological capabilities,' Strategic Management Journal, 17, 21-38.

Tying the Knot in Las Vegas. http://www.examiner.com Accessed 8/27/09.

White, H.C. (1981), ‘Where do markets come from?’ American Journal of Sociology, 87, 517-547.

White, H.C. (2002), Markets from networks. Princeton University Press: Princeton, NJ.

Whittington, K.B., W.W. Powell and J. Owen-Smith (2009), ‘Networks, propinquity, and innovation in knowledge-intensive industries,' Administrative Science Quarterly, 54, 90122. 
Table 1

Proportions of Manufacturing Establishments for Six U.S. Communities 1976

\begin{tabular}{|c|c|c|c|c|c|c|c|}
\hline & & $\begin{array}{c}\text { Los } \\
\text { Angeles }\end{array}$ & $\begin{array}{l}\text { New York } \\
\text { City }\end{array}$ & Chicago & Boston & Bakersfield & Dickinson \\
\hline 20 & $\begin{array}{l}\text { Food and Kindred } \\
\text { Products }\end{array}$ & .03 & .03 & .05 & .05 & .10 & .28 \\
\hline 21 & Tobacco Products & 0 & 0 & 0 & 0 & 0 & 0 \\
\hline 22 & Textile Mill Products & .01 & .06 & .01 & .02 & .01 & .01 \\
\hline 23 & $\begin{array}{l}\text { Apparel and Other Textile } \\
\text { Products }\end{array}$ & .07 & .23 & .03 & .06 & .02 & .01 \\
\hline 24 & $\begin{array}{l}\text { Lumber and Wood } \\
\text { Products }\end{array}$ & .03 & .02 & .02 & .03 & .06 & .04 \\
\hline 25 & Furniture and Fixtures & .05 & .04 & .03 & .04 & .06 & .04 \\
\hline 26 & Paper and Allied Products & .01 & .02 & .03 & .02 & 0 & 0 \\
\hline 27 & Printing and Publishing & .11 & .16 & .16 & .16 & .11 & .18 \\
\hline 28 & $\begin{array}{l}\text { Chemicals and Allied } \\
\text { Products }\end{array}$ & .04 & .04 & .06 & .05 & .09 & .04 \\
\hline 29 & $\begin{array}{l}\text { Petroleum and Coal } \\
\text { Products }\end{array}$ & 0 & 0 & .01 & 0 & .05 & .05 \\
\hline 30 & $\begin{array}{l}\text { Rubber and Misc. Plastics } \\
\text { Products }\end{array}$ & .04 & .02 & .04 & .03 & .03 & .01 \\
\hline 31 & $\begin{array}{l}\text { Leather and Leather } \\
\text { Products }\end{array}$ & .01 & .02 & .01 & .04 & .01 & .01 \\
\hline 32 & $\begin{array}{l}\text { Stone, Clay and Glass } \\
\text { Products }\end{array}$ & .03 & .02 & .03 & .03 & .09 & .06 \\
\hline 33 & Primary Metal Industries & .02 & .01 & .03 & .02 & .01 & .01 \\
\hline 34 & Fabricated Metal Products & .10 & .06 & .13 & .09 & .05 & .01 \\
\hline 35 & $\begin{array}{l}\text { Industrial Machinery and } \\
\text { Equip. }\end{array}$ & .19 & .07 & .18 & .14 & .20 & .20 \\
\hline 36 & $\begin{array}{l}\text { Electronic and Other } \\
\text { Electric Equip. }\end{array}$ & .08 & .05 & .07 & .09 & .04 & .02 \\
\hline 37 & Transportation Equip. & .05 & .01 & .02 & .02 & .03 & .01 \\
\hline 38 & $\begin{array}{l}\text { Instruments and Related } \\
\text { Products }\end{array}$ & .03 & .03 & .03 & .05 & .01 & 0 \\
\hline 39 & $\begin{array}{l}\text { Misc. Manufacturing } \\
\text { Industries }\end{array}$ & .06 & .10 & .06 & .05 & .02 & .03 \\
\hline
\end{tabular}


Table 2

Market Distances Among Six U.S. Communities 1976

\begin{tabular}{|lccccc|}
\hline & 1. & 2. & 3. & 4. & 5. \\
\hline 1. Los Angeles & & & & & \\
2. New York & 0.33 & & & & \\
3. Chicago & 0.13 & 0.35 & & & \\
4. Boston & 0.19 & 0.29 & 0.14 & & \\
5. Bakersfield & 0.33 & 0.4 & 0.19 & 0.19 & \\
6. Dickinson & 0.39 & 0.43 & 0.33 & 0.23 & 0.09 \\
\hline
\end{tabular}


Table 3

Descriptive Statistics and Correlations

\begin{tabular}{|c|c|c|c|c|c|c|c|}
\hline & Mean & Std. Dev. & 1. & 2. & 3. & 4. & 5. \\
\hline 1. Firm foundings & 142.736 & 433.409 & & & & & \\
\hline 2. Firm exits & 119.25 & 391.644 & .971 & & & & \\
\hline 3. Human population density & 133.043 & 325.845 & .672 & .769 & & & \\
\hline 4. Niche width & .889 & .037 & .066 & .054 & .089 & & \\
\hline 5. Industry mix growth & .044 & .081 & .016 & .001 & .006 & .033 & \\
\hline 6. Skilled work force & .001 & 1.006 & .429 & .423 & .55 & .311 & .016 \\
\hline 7. Personal wealth & -.05 & .94 & .405 & .369 & .346 & .045 & -.036 \\
\hline 8. Average wage (thousands) & 14.248 & 2.951 & .263 & .254 & 245 & .032 & -.463 \\
\hline 9. Wage dispersion (thousands) & 7.598 & 5.833 & -.011 & -.011 & -.016 & -.068 & -.031 \\
\hline $\begin{array}{l}\text { 10. Adjacent firm foundings weighted by } \\
\text { distance }\end{array}$ & 12.822 & 23.136 & .23 & .244 & .366 & .085 & .021 \\
\hline $\begin{array}{l}\text { 11. Adjacent firm exits weighted by } \\
\text { distance }\end{array}$ & 11.303 & 25.561 & .205 & .219 & .332 & -.275 & -.018 \\
\hline 12. Non-local market niche overlap x100 & 157 & .049 & -.146 & -.121 & .04 & .389 & .019 \\
\hline 13. Local market niche overlap x100 & 1.321 & .495 & .106 & .133 & .339 & .281 & .004 \\
\hline
\end{tabular}

\begin{tabular}{|llllllll|}
\hline & 6. & 7. & 8. & 9. & 10. & 11. & 12. \\
\hline 7. Personal wealth & .434 & & & & & & \\
8. Average wage (thousands) & .335 & .426 & & & & & \\
9. Wage dispersion (thousands) & .021 & .002 & .069 & & & & \\
10. Adjacent firm foundings weighted by distance & .397 & .396 & .197 & .018 & & & \\
11. Adjacent firm exits weighted by distance & .36 & .371 & .184 & .014 & .975 & & \\
12. Non-local market niche overlap x100 & .349 & -.236 & .022 & .017 & -.064 & -.047 & \\
13. Local market niche overlap x100 & .641 & .077 & .164 & .006 & .236 & .213 & .606 \\
\hline
\end{tabular}


Table 4

Negative Binomial Regressions of Firm Exits and Firm Foundings by LMA with LMA-fixed effects

\begin{tabular}{|c|c|c|c|c|}
\hline & \multicolumn{2}{|c|}{ Firm Foundings } & \multicolumn{2}{|c|}{ Firm Exits } \\
\hline & 1. & 2. & 3. & 4. \\
\hline Human population & .022 & .0127 & $.135^{\bullet}$ & $.142 \bullet$ \\
\hline density & $(.024)$ & $(.025)$ & $(.025)$ & $(.024)$ \\
\hline \multirow[t]{2}{*}{ Niche width } & -.458 & -.464 & -.822 & -.984 \\
\hline & $(.657)$ & $(.657)$ & $(.666)$ & $(.668)$ \\
\hline \multirow[t]{2}{*}{ Industry mix growth } & $1.089 \bullet$ & $1.011^{\bullet}$ & $.639 \bullet$ & $.675^{\bullet}$ \\
\hline & $(.081)$ & $(.082)$ & $(.091)$ & $(.093)$ \\
\hline \multirow[t]{2}{*}{ Skilled work force } & $.063^{\bullet}$ & $.054 \bullet$ & $.112 \bullet$ & $.119 \bullet$ \\
\hline & $(.023)$ & $(.022)$ & $(.023)$ & $(.024)$ \\
\hline \multirow[t]{2}{*}{ Personal wealth } & $.078 \bullet$ & $.075 \bullet$ & .007 & .007 \\
\hline & $(.013)$ & $(.013)$ & $(.016)$ & $(.016)$ \\
\hline \multirow[t]{2}{*}{ Average wage } & $.025^{\bullet}$ & $.022 \bullet$ & $.007 \bullet$ & $.007 \bullet$ \\
\hline & $(.002)$ & $(.002)$ & $(.003)$ & $(.003)$ \\
\hline \multirow[t]{2}{*}{ Wage dispersion } & .001 & .001 & .000 & .000 \\
\hline & $(.001)$ & $(.001)$ & $(.001)$ & $(.001)$ \\
\hline Adjacent dependent & .001 & .001 & $.002 \bullet$ & $.002 \bullet$ \\
\hline $\begin{array}{l}\text { variable weighted by } \\
\text { geographical distance }\end{array}$ & $(.001)$ & $(.001)$ & $(.001)$ & $(.001)$ \\
\hline \multirow[t]{2}{*}{ Nonlocal niche overlap } & & $-.305 \bullet$ & & $.249 \bullet$ \\
\hline & & $(.116)$ & & (.123) \\
\hline \multirow[t]{2}{*}{ Local niche overlap } & & $.412 \bullet$ & & $-.239 \bullet$ \\
\hline & & $(.11)$ & & $(.116)$ \\
\hline \multirow[t]{2}{*}{ Constant } & $3.724 \bullet$ & 3.628 • & $3.902 \bullet \bullet$ & $4.617 \bullet$ \\
\hline & $(.596)$ & (.798) & $(.599)$ & $(.901)$ \\
\hline Log likelihood & $-5,574.16$ & $-5,567.38$ & $-5,540.42$ & $-5,537.93$ \\
\hline
\end{tabular}

$\mathrm{N}=1900 ; \bullet<.05$ 
Figure 1

Market Niches of Six U.S. Communities, 1976

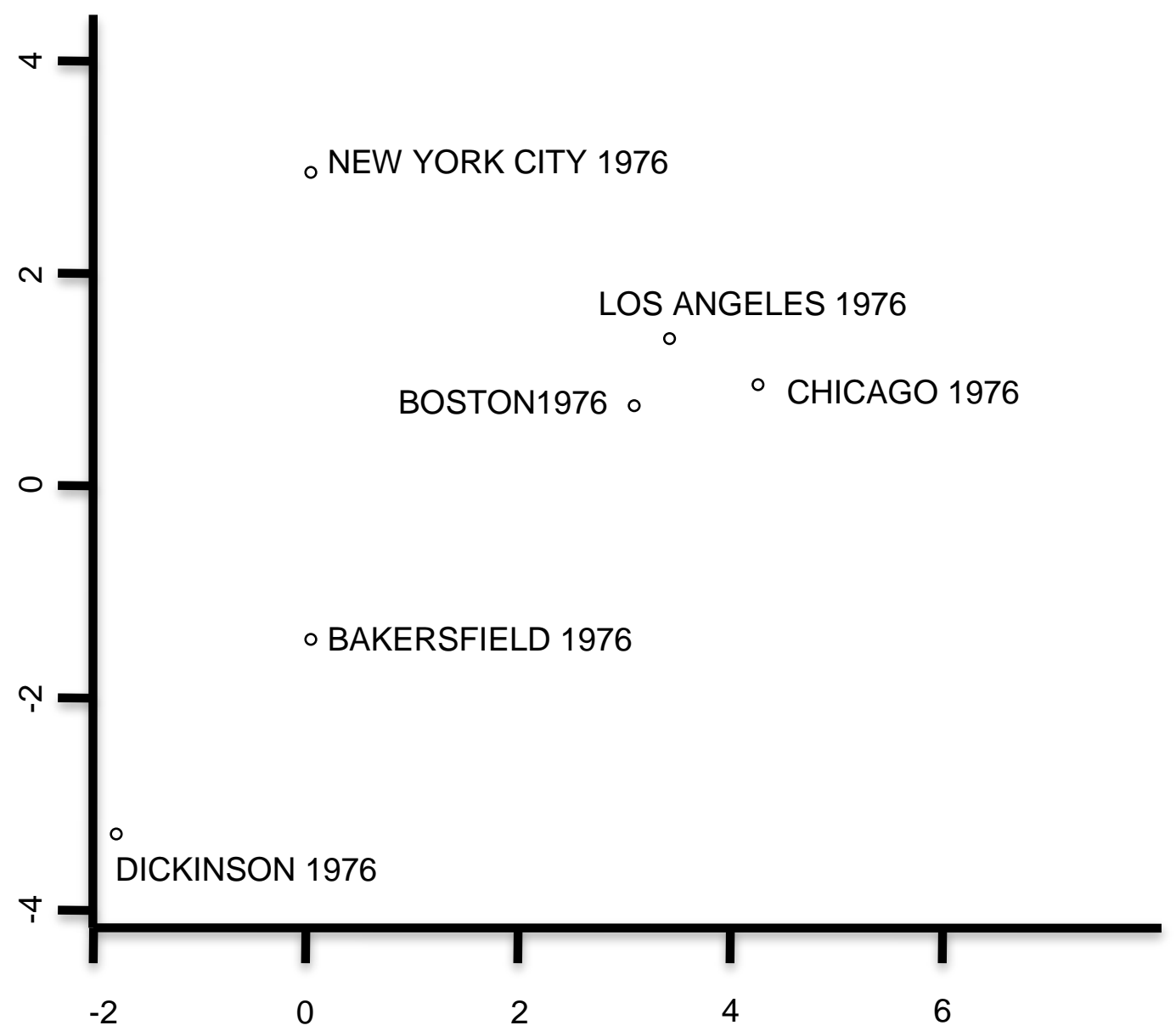


Figure 2

Market Niches of Six U.S. Communities, 1976 and 1986

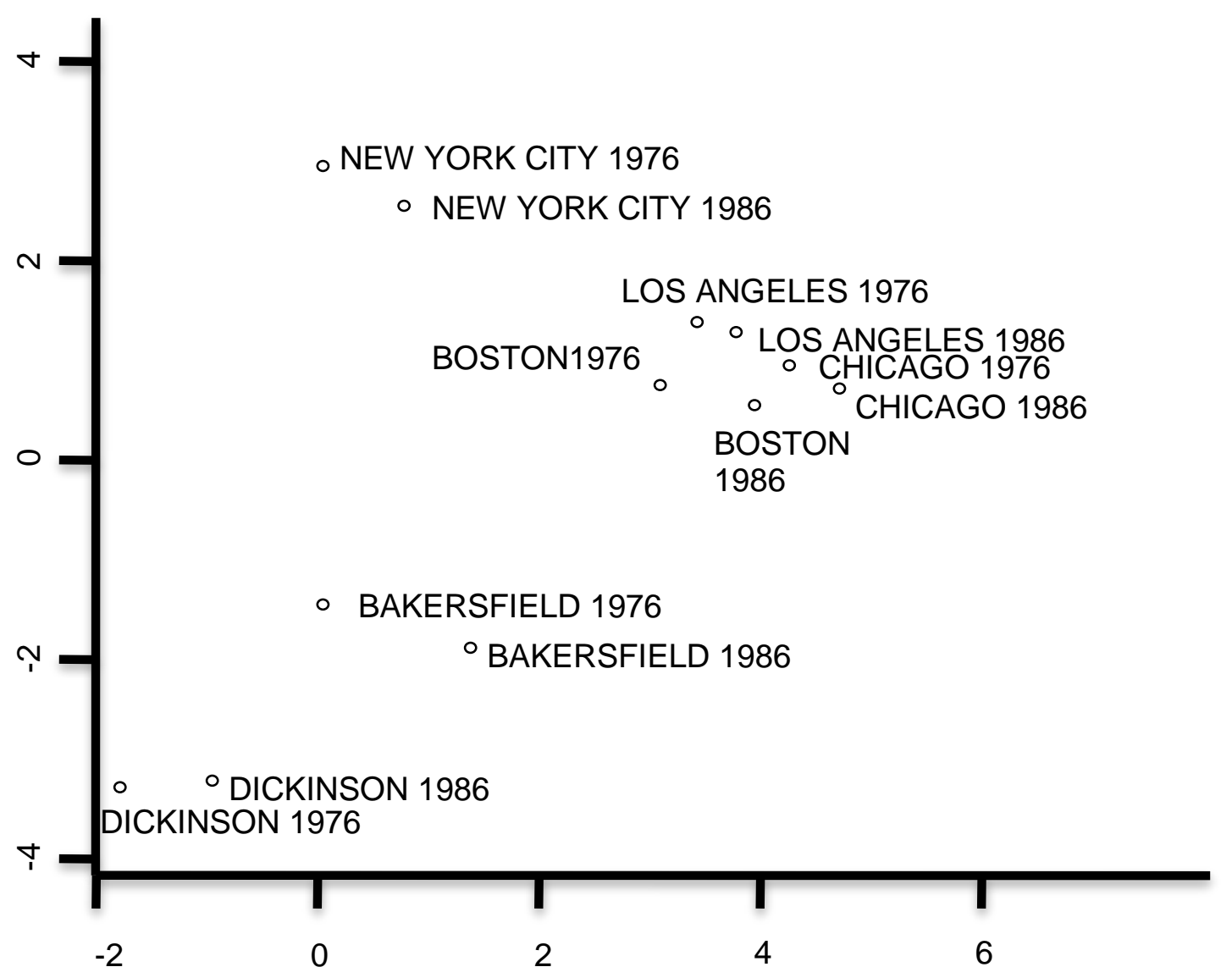

